\title{
Differences in Blossom-end Rot Resistance in Tomato Cultivars is Associated with Total Ascorbate rather than Calcium Concentration in the Distal End Part of Fruits per se
}

\author{
Moalla Rached ${ }^{1}$, Baldet Pierre' ${ }^{2}$, Gibon Yves $^{2}$, Chiaki Matsukura $^{3}$, Toru Ariizumi ${ }^{3}$, \\ Hiroshi Ezura ${ }^{3}$ and Naoya Fukuda ${ }^{3 *}$ \\ ${ }^{1}$ Graduate School of Life and Environmental Sciences, University of Tsukuba, Tsukuba 305-8572, Japan \\ ${ }^{2}$ Institut National de la Recherche Agronomique (INRA), Université de Bordeaux, Unité Mixte de Recherche 1332 Biologie du \\ Fruit et Pathologie, Bordeaux 33882, France \\ ${ }^{3}$ Faculty of Life and Environmental Sciences, University of Tsukuba, Tsukuba 305-8572, Japan
}

Calcium is widely accepted as the main factor responsible for blossom-end rot (BER) appearance in tomato (Solanum lycopersicum L.) fruit. However, reactive oxygen species (ROS), which can damage plant tissues have also been proposed to initiate BER appearance in tomatoes and other fruit-bearing vegetables. Ascorbate, the major antioxidant in tomato fruit, is generally lower during green fruit development, which corresponds to the stage of BER appearance. Accordingly, one hypothesis is that tomato cultivars with a lower susceptibility to BER under salt stress have higher ascorbate contents and thus better control of ROS levels. In this study, to clarify the relationship between BER incidence and oxidative stress, two BER resistant cultivars, 'Managua RZ' and 'House Momotaro' and one BER-susceptible cultivar 'Reiyoh', were cultivated under salinity or standard nutrient solution (control) conditions. Calcium, potassium, magnesium, total hydro-soluble antioxidants, and ascorbate concentrations were measured in the distal pericarp 1 to 2 days prior to symptom appearance and during symptom appearance in healthy and affected fruits. When salt stress was applied, only BER-resistant cultivars showed a significant increase in ascorbate contents prior to BER appearance as compared with their levels under the control condition. In contrast, pre-BER $\mathrm{Ca}^{2+}$ concentrations did not associate with the BER susceptibility of each cultivar. Interestingly, 'Reiyoh' showed much higher $\mathrm{K}^{+} / \mathrm{Ca}^{2+}$ and $\left(\mathrm{K}^{+}+\mathrm{Mg}^{2+}\right) / \mathrm{Ca}^{2+}$ ratios than the two other cultivars in healthy fruits due to a strong tendency towards lowered $\mathrm{Ca}^{2+}$ concentrations. A similar tendency was also observed in apple "bitter pit". The ability to increase the fruit antioxidant capacity and maintain mineral balance under salt stress conditions may explain the resistance to BER development in highly resistant cultivars, probably by the avoidance of oxidative-induced cell necrosis and stabilization of the cell membranes, respectively.

Key Words: ascorbate, BER, cultivar, oxidative stress, ROS.

\section{Introduction}

Blossom-end rot (BER) is a physiological disorder in tomatoes and other fruit bearing vegetables. In tomatoes, it appears as a water-soaked area at the distal part (style-end) of green fruits aged 12 to 15 day after anthesis. It rapidly develops into black necrotic lesions and can cause severe yield losses (Geraldson, 1955; Spurr, 1959; Taylor and Locascio, 2004). Calcium is widely

Received; October 19, 2017. Accepted; December 4, 2017.

First Published Online in J-STAGE on February 16, 2018.

* Corresponding author (E-mail: fukuda.naoya.ka@u.tsukuba.ac.jp). accepted to be the main factor causing BER (Taylor and Locascio, 2004). In fact, BER appears when calcium is lacking in the distal part of tomato fruit (Bradfield and Guttridge, 1984). This calcium deficiency can be triggered by several factors including low calcium in the nutrient solution (Van Goor, 1968), nutrient imbalances (Hao and Papadopoulos, 2004; Raleigh and Chucka, 1944; Van Der Boon, 1973), salinity (Aktas et al., 2003; Bradfield and Guttridge, 1984; Robbins, 1937; Tabatabaie et al., 2004), drought (Pill and Lambeth, 1980), and low atmospheric humidity (Bradfield and Guttridge, 1984); all factors that can limit plant calcium uptake and translocation to the fruit (Taylor and 
Locascio, 2004).

At the cellular level, BER appears with low levels of $\mathrm{Ca}^{2+}$ in plasma membranes (Suzuki et al., 2003). The development of BER is described as an increase in cell membrane leakage, followed by plasmolysis and membrane breakdown that lead to the water-soaked symptoms and subsequent necrosis of tissues (Simon, 1978; Suzuki et al., 2003; Van Goor, 1968). These facts can be explained by the need for $\mathrm{Ca}^{2+}$ for cell membrane stability and semi-permeability (Marschner, 1995). Several authors tried to determine the critical calcium concentration under which BER is triggered in the fruit distal pericarp, but no consensus was established (Saure, 2001). In some cases, total $\mathrm{Ca}^{2+}$ concentration was even higher in BER fruits than healthy ones (Nonami et al., 1995). Based on these facts, Saure (2001) concluded that stress factors may be involved in BER appearance rather than $\mathrm{Ca}^{2+}$ per se.

Reactive oxygen species (ROS) were proposed to be involved in the causal mechanism of BER development (Aktas et al., 2003). ROS are a major player in stressrelated mechanisms. ROS are well known to be involved in triggering cell damage and death by membrane lipid peroxidation, leading to increased membrane leakage and cell lysis (Van Breusegem and Dat, 2006), a very similar mechanism to what happens during BER development. Interestingly, the appearance of BER was found to correspond to the stages of fruit development at which the production of ROS was maximal while scavenging was limited in pepper fruits (Aktas et al., 2003). ROS levels can be controlled by several enzymatic and non-enzymatic mechanisms. For enzymatic control, enzymes like superoxide dismutase (SOD), peroxidase, and catalase can be deployed to control ROS levels, while for non-enzymatic control, two main metabolites, ascorbate and glutathione, are produced and recycled to protect the plant from oxidative damage (Mittler, 2002).

In tomato fruit, ascorbate is known to be the major antioxidant (Francesco et al., 2005). Ascorbate concentrations were reported to be limited during green fruit development (Torres and Andrews, 2006), which is also the stage of BER appearance (Spurr, 1959). Ascorbate concentration in tomato fruit was also found to be reduced under high salinity (D'Amico et al., 2003), heat (Massot et al., 2013) and light stress conditions (Ioannidi et al., 2009; Torres et al., 2006), all conditions favorable for BER appearance (Olle and Bender, 2009). Interestingly, fruit calcium concentration, the major known factor in BER initiation, has also been proposed to be positively correlated with ascorbate levels in tomato fruit (Premuzic et al., 1998) and the conditions favorable to BER, like salinity, drought and heat stress, were also found to increase ROS levels in tomato fruit (Leyva et al., 2013; Murshed et al., 2013, 2014). Taking all these facts into account, there seems to be a connection between conditions that lower ascorbate concentra- tions and increase ROS levels to the susceptibility toward BER in tomatoes.

Therefore, we hypothesize that ascorbate is a major player in the control of BER appearance by protecting distal fruit cell membranes from oxidative damage. In our preliminary experiment, we could show the differences in BER susceptibility among some different tomato cultivars under saline conditions. Indeed, one cultivar showed high tolerance to BER under saline conditions regardless of its low $\mathrm{Ca}^{2+}$ concentrations. From these results, we expect that cultivars with less susceptibility to BER show higher ascorbate concentrations and antioxidant capacity prior to, and during the stages of BER appearance.

The objective of this study was to show the possible role of ascorbate as a fruit antioxidant in the protection from BER-inducing conditions. For that, three cultivars with different susceptibilities to BER were cultivated with a standard nutrient solution and a BER-inducing one, with high salinity and enriched with $\mathrm{SO}_{4}{ }^{2-}, \mathrm{K}^{+}$, and $\mathrm{Mg}^{2+}$. The total hydrosoluble antioxidant, ascorbate, glutathione, and mineral concentrations were measured in fruit samples taken 1 to 2 days prior to symptom appearance and during symptom appearance in healthy and affected fruits. The status of each variable measured at each sampling stage, helped to clarify their degree of involvement in the resistance to BER appearance.

\section{Materials and Methods}

\section{Plant materials and growing conditions}

The experiment was conducted in a greenhouse of the Agricultural and Forestry Research Center in the University of Tsukuba, from April 29 until July 31 2016.

Three indeterminate type tomato (Solanum lycopersicum L.) cultivars with different susceptibilities to BER were used. These cultivars were selected after screening for BER susceptibility was performed on 8 cultivars from Japanese and European origins. The screening was performed by growing plants under salt stress conditions and three cultivars, in which $\mathrm{Ca}^{2+}$ concentrations in the distal pericarp and BER were not associated, were selected: 'Managa RZ' (RijkZwaan, De Lier, Netherlands) and 'House Momotaro', shown as 'H. Momotaro' in figures, (Takii \& Co., Ltd., Kyoto, Japan) are BER-resistant cultivars, and 'Reiyoh' (Sakata Seed Co., Kanagawa, Japan) is a sensitive one. Seedlings were grown in compressed peat Jiffy pots (Jiffy International AS, Kristiansand, Norway) filled with coir substrate. Pots were set into a deep flow technique (DFT) system with Otsuka-A recirculating nutrient solution (Otsuka-A; Otsuka Chemical Co., Ltd., Osaka, Japan) adjusted to an electrical conductivity (EC) of $1.2 \mathrm{dS} \cdot \mathrm{m}^{-1}$ and $\mathrm{pH}$ of 5.8-6.5 by adding a $1 \mathrm{M}$ sulfuric acid solution. When 5 to 6 true leaves were fully expanded, twelve plants from each cultivar were 
selected and transplanted into each treatment area located in one of two different gutters of a nutrient film technique (NFT) cultivation system in a glasshouse. An Enshi nutrient solution containing $16 \mathrm{me} \cdot \mathrm{L}^{-1} \mathrm{NO}_{3}^{-}$, $4 \mathrm{me} \cdot \mathrm{L}^{-1} \mathrm{SO}_{4}{ }^{2-}, 4 \mathrm{me} \cdot \mathrm{L}^{-1} \mathrm{PO}_{4}{ }^{3-}, 8 \mathrm{me} \cdot \mathrm{L}^{-1} \mathrm{~K}^{+}, 4 \mathrm{me} \cdot \mathrm{L}^{-1}$ $\mathrm{Mg}^{2+}, 8 \mathrm{me} \cdot \mathrm{L}^{-1} \mathrm{Ca}^{2+}$, and $4 \mathrm{me} \cdot \mathrm{L}^{-1} \mathrm{NH}_{4}^{+}$having an EC of $1.6-1.7 \mathrm{dS} \cdot \mathrm{m}^{-1}$ was used and $\mathrm{pH}$ was maintained at $5.8-6.5$ in the same way described above. Planting density was 2.35 plants $\cdot \mathrm{m}^{-2}(26.5 \mathrm{~cm} \times 160 \mathrm{~cm})$ and plants were trained to a single stem. All lateral shoots were removed as they appeared and plants were pinched at three leaves above the fourth truss. Fully opened flowers were manually pollinated and their fruit age was monitored in terms of days after anthesis (DAA). The number of fruits set in each truss was limited to five starting from flower pollination to keep fruit growth rates close to their potentials in order to better express the BER susceptibility of each cultivar. Irrigation was applied for 15 min every hour during daytime and was done five times during the night. When flowering began, the nutrient solution treatment was started. The same Enshi nutrient solution was maintained for the control treatment while the BER-inductive treatment received a similar nutrient solution with $6.5 \mathrm{me} \cdot \mathrm{L}^{-1}$ $\mathrm{SO}_{4}{ }^{2-}, 4 \mathrm{me} \cdot \mathrm{L}^{-1} \mathrm{~K}^{+}$, and $2.5 \mathrm{me} \cdot \mathrm{L}^{-1} \mathrm{Mg}^{2+}$ added. The BER-inductive (BERi) nutrient solution's EC value was gradually raised to $8 \mathrm{dS} \cdot \mathrm{m}^{-1}$ by using $\mathrm{NaCl}$ to avoid osmotic shock. This target EC was reached in 3 days, prior to full bloom. It was technically impossible to maintain the nutrient composition as it was set when first injected in the NFT tanks, so to insure that the composition was maintained as close as possible to the target ion values, the nutrient solution was exchanged once per week prior to flowering and twice per week from the start of flowering as plants grew bigger and consumed more water. Preliminary experiments showed that this nutrient solution induced higher incidences of BER than other ones with equivalent EC using only $\mathrm{NaCl}$, or solutions enriched only with $\mathrm{K}^{+}$and $\mathrm{Mg}^{2+}$. Also, $\mathrm{Ca}^{2+}$ concentration was maintained similar to the control in this nutrient solution to avoid $\mathrm{Ca}^{2+}$ deficiency symptoms in the plant itself. A shadowing net was placed above the culture from 9 a.m. to 3 p.m. to limit high solar radiation in summer conditions. Also, the top and side ventilation windows were automatically opened to prevent the air temperature from increasing.

\section{BER appearance, averaged fruit fresh weight, and BER incidence}

The average age of BER appearance was calculated for every plant in terms of DAA. Then, BER appearance was calculated by summing the obtained values, and dividing them by the corresponding number of plants. Averaged fruit fresh weight was calculated by summing the fresh weight of mature fruits in the first truss for each plant, and dividing them by the corresponding number of fruits. BER incidence was esti- mated from six tomato plants for each combination of cultivar/nutrient solution treatment. It was expressed in terms of percentage of affected fruits from the total number of fruits in the first truss.

\section{Fruit sample preparation}

Sampling was performed on "BER-affected" fruits on the day of symptom appearance. The age of the affected fruit was noted and "healthy fruits" of the same age were collected from both the control and BERinductive treatments. Fruits aged 1 to 2 days younger than the BER affected fruits were also collected from both nutrient solution treatments. These fruit pericarp samples were sliced from the proximal (peduncle side) and distal (style side) part of the fruit, frozen in liquid nitrogen, ground into a fine powder, and stored at $-80^{\circ} \mathrm{C}$.

\section{Fruit mineral analysis}

To determine the mineral composition in tomato pericarp, samples were freeze-dried for $48 \mathrm{~h}$. After measuring dry weight, samples were placed into a muffle at $550^{\circ} \mathrm{C}$ for $4 \mathrm{~h}$ for ashing. The obtained ash was dissolved with $200 \mu \mathrm{L}$ of water before adding $200 \mu \mathrm{L}$ of concentrated $\mathrm{HCl}$. The dissolved ash was then further diluted to determine calcium, potassium, and magnesium concentrations. Each element's concentration was measured by a polarized Zeeman atomic absorption spectrophotometer (ZA3300; Hitachi High-Technologies Co., Tokyo, Japan).

\section{Total hydrosoluble antioxidant assay}

The azino-bis(3-ethylbenzothiazolin-6-sulfonic) acid (ABTS) assay was used to determine the total hydrosoluble antioxidant concentration. The assay was performed following the method described by Marc et al. (2016) which was adapted to microplates. Briefly, an aqueous $\mathrm{ABTS}^{+}$solution was prepared by the oxidation reaction of ABTS (Sigma Aldrich, Missouri, USA) with $\mathrm{MnO}_{2}$. 50 to $100 \mathrm{mg}$ of frozen powder from each sample was dispatched into micro tubes (Micronic, Lelystad, Netherlands). $500 \mu \mathrm{L}$ of $50 \%$ ethanol solution was added to the frozen powder for hydrosoluble antioxidant extraction. After mixing, tubes were centrifuged for $5 \mathrm{~min}$ at $4^{\circ} \mathrm{C} .5 \mu \mathrm{L}$ of the supernatant was added to $300 \mu \mathrm{L}$ of the $\mathrm{ABTS}^{+}$solution. The presence of antioxidants in the samples resulted in the discoloration of the mixture that was measured at $734 \mathrm{~nm}$. This discoloration magnitude was proportional to the total hydrosoluble antioxidant capacity of the sample and was calculated using an ascorbate standard curve.

\section{Ascorbate and glutathione assays}

Total and reduced ascorbates were measured according to the procedure described by Stevens et al. (2006) with slight modifications. Briefly, ascorbate was extracted from 50 to $100 \mathrm{mg}$ of frozen pericarp powder in 
$500 \mu \mathrm{L}$ of cold $6 \%$ phosphoric acid. After vigorous mixing, the homogenate was centrifuged at maximum speed $(4000 \mathrm{rpm} ; 2271 \times \mathrm{g})$ and $4^{\circ} \mathrm{C}$ for $25 \mathrm{~min}$. For total ascorbate measurement, dehydroascorbate was reduced by incubating with $5 \mathrm{mM}$ dithiothréitol (DTT) followed by a reaction with $40 \mathrm{mM}$ N-ethylmaleimide (NEM) to eliminate excess DTT. For the reduced ascorbate, the same procedure was followed but DTT and NEM were replaced by the same volume of $0.4 \mathrm{M}$ phosphate buffer, $\mathrm{pH}$ 7.4. A chromogenic reagent was prepared by mixing $\mathrm{A}$ and $\mathrm{B}$ solutions, for which the compositions were as follows: solution A: $31 \%$ orthophosphoric acid, $4.6 \% \mathrm{w} / \mathrm{v}$ trichloroacetic acid (TCA), and $0.6 \% \mathrm{w} / \mathrm{v}$ iron chloride; solution B: $4 \% 2$ 2,2dipyridyl (w/v made up in 70\% ethanol); and solutions $\mathrm{A}$ and $\mathrm{B}$ were mixed 2.75 parts (A) to 1 part (B). After incubation, the absorbance was read at $520 \mathrm{~nm}$ and ascorbate concentration was calculated using an ascorbate standard curve. A glutathione assay was performed with the same supernatant prepared for the ascorbate assay, according to the protocol described by Griffith (1980). The production of 5-thio-2-nitrobenzoic acid (TNB) was used to measure the total glutathione concentration present in the extract. TNB was produced by the reaction of reduced glutathione (GSH) with 5,5'-dithiobis-2nitrobenzoic acid (DTNB). The reaction was performed in the presence of glutathione reductase and started by the addition of $2 \mathrm{mM}$ NADPH. The production rate of $\mathrm{TNB}$, absorbing at $405 \mathrm{~nm}$, was proportional to the concentration of GSH in the extract. Total glutathione concentration was calculated using a GSH standard curve. For the glutathione disulphide assay (Oxidized glutathione or GSSG), $50 \mu \mathrm{L}$ of the extract was incubated in the presence of $1 \mu \mathrm{L}$ of $0.5 \mathrm{M} 4$-vinylpirdine (4-vpd) to mask the presence of reduced glutathione. The same reaction described above was then performed, and GSSG concentration was calculated against a GSSG standard.

\section{Statistical analysis}

Statistical analysis was performed using IBM SPSS
Statistics for Windows, Version 24.0 (IBM Co., NY, USA). A two-way ANOVA $(P<0.05)$ with "Nutrient solution" and "Cultivars" as independent variables, then a (post-hoc) Tukey-HSD test was conducted.

\section{Results}

Average fruit fresh weight, BER incidence, and BER appearance

In the control treatment, average fruit fresh weight was $131.4 \mathrm{~g}, 112.8 \mathrm{~g}$, and $101.6 \mathrm{~g}$ for 'Managua RZ', 'Reiyoh', and 'House Momotaro', respectively (Fig. 1A). In the BERi treatment, fruit fresh weight was significantly decreased to around $50 \mathrm{~g}$ per fruit for all three cultivars.

No BER was observed under the control condition (data not shown), while symptom incidence appeared differently between cultivars under the BERi condition (Fig. 1B). Namely, 'Reiyoh' showed the highest BER incidence of $63.9 \%$. In contrast, 'Managua RZ' and 'House Momotaro' had significantly lower BER incidences of $2.8 \%$ and $11.7 \%$, respectively. Those symptoms appeared 11 to 13 DAA for all three cultivars (Fig. 1C).

\section{Distal pericarp mineral concentrations}

Mineral concentrations were measured in the distal pericarp 1 to 2 days prior to symptom appearance (preBER) and also in healthy and affected fruits on the day symptoms appeared (Table 1). No significant differences were observed for $\mathrm{K}^{+}$concentration at each observation stage between cultivars, and treatments. For $\mathrm{Mg}^{2+}$ concentration, at the pre-BER stage, only 'Reiyoh' had a significant increase of $22 \%$ compared to the control, which made its concentration higher than the two other cultivars under the same treatment. In healthy fruits, 'Reiyoh' also tended to have more $\mathrm{Mg}^{2+}$ than the other cultivars. In the affected fruits, both Japanese cultivars 'Reiyoh' and 'House Momotaro' had more $\mathrm{Mg}^{2+}$ than 'Managua $\mathrm{RZ}$ '.

In the pre-BER stage, $\mathrm{Ca}^{2+}$ concentrations were kept
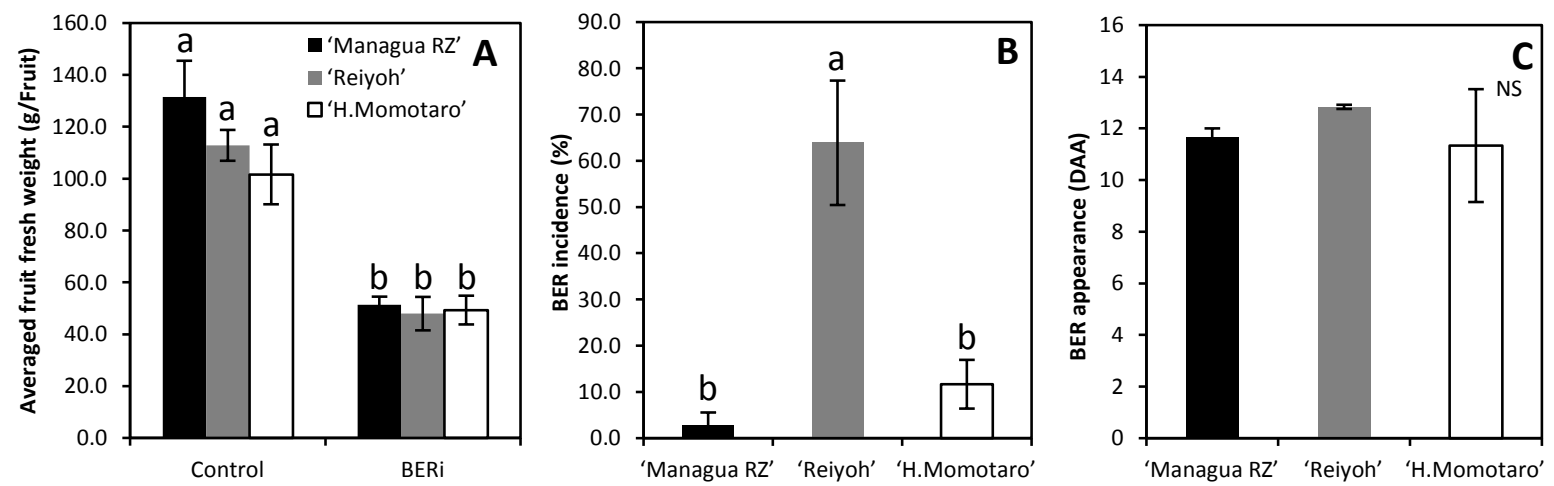

Fig. 1. (A) Fruit fresh weight in tested cultivars $(n=5-6)$ and (B) BER incidence under the BER-inductive condition $(n=6)$. $(C)$ BER appearance estimated as the averaged fruits age where BER symptoms appeared in tested cultivars under the BER-inductive condition $(\mathrm{n}=3-5)$. Different letters between cultivars represent a statistical difference in BER incidence $(P<0.05)$. NS: ANOVA was not significant $(P<0.05)$. Data are means \pm standard error (SE). 
Table 1. Potassium $\left(\mathrm{K}^{+}\right)$, magnesium $\left(\mathrm{Mg}^{2+}\right)$, and calcium $\left(\mathrm{Ca}^{2+}\right)$ concentrations and ratios of $\mathrm{K} / \mathrm{Ca}$ and $(\mathrm{K}+\mathrm{Mg}) / \mathrm{Ca}$ in the distal pericarp of PreBER, healthy and affected tomato fruits under standard nutrient solution treatment (Control) and BER inductive nutrient solution treatment (BERi) with a summary of the Two-way ANOVA analysis. Data is expressed as percentage (\%) of dry weight.

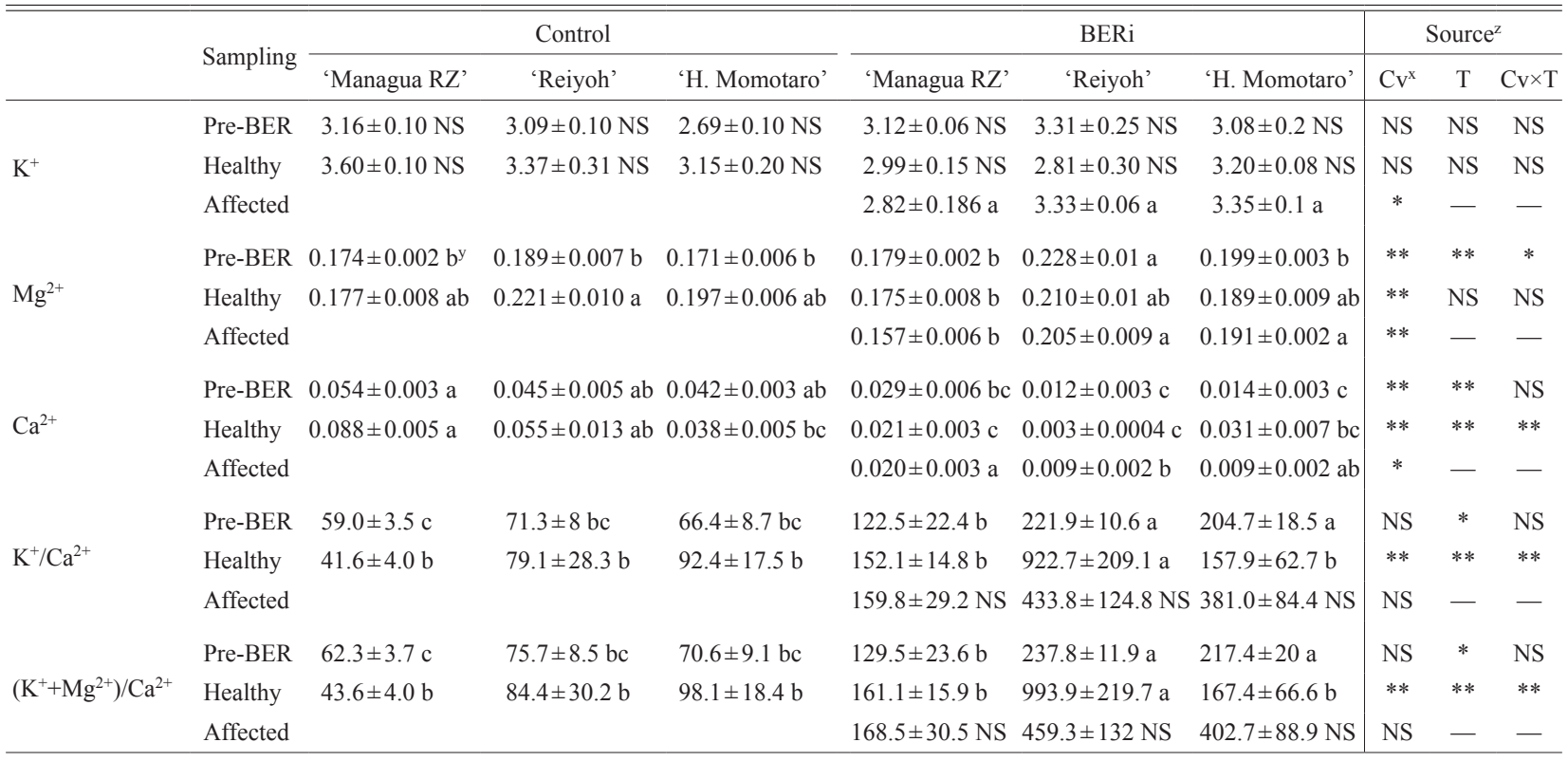

${ }^{z} \mathrm{NS}, *$, or **: The effect was not significant $(P>0.05)$, significant $(0.01<P<0.05)$, or highly significant $(P<0.01)$.

y Different letters represent a statistical difference with Tukey-HSD test $(P<0.05)$. Data are means \pm standard error $(\mathrm{SE})$. $(\mathrm{n}=3-5)$

"Cv: "cultivar"; T: "nutrient solution treatment".

above $0.04 \%$ for all cultivars under the control condition and were significantly decreased by BERi condition treatment. It was $0.029 \%$ for 'Managua RZ' and tended to be even lower, around $0.01 \%$, for the two other cultivars. In the healthy fruits, control treatment fruits of 'Managua RZ' and 'Reiyoh' had more $\mathrm{Ca}^{2+}$ than in the previous stage, reaching $0.088 \%$ and $0.055 \%$ respectively. However, 'House Momotaro' maintained similar levels. The decrease in $\mathrm{Ca}^{2+}$ concentration under the effect of BERi treatment was even more drastic at this stage for 'Managua RZ' and 'Reiyoh', with fruits showing concentrations of $0.021 \%$ and $0.003 \%$, respectively; there was a strong interaction between cultivars and nutrient solution treatment too $(P<0.01)$. Interestingly, 'House Momotaro' maintained comparable concentrations to the control in the BERi treatment. Affected fruits showed $\mathrm{Ca}^{2+}$ concentrations of $0.02 \%$ for 'Managua RZ' and lower levels, around $0.009 \%$, for both remaining cultivars.

BERi treatment increased $\mathrm{K}^{+} / \mathrm{Ca}^{2+}$ ratios in pre-BER fruits by 2-3 fold for all cultivars compared with the control, and the resulting ratio was higher for Japanese cultivars than for 'Managua RZ'. More than a 10-fold increase was observed for 'Reiyoh' in the healthy fruits as compared with the control condition. The resulting ratio of 923 was 6 times higher than the values observed in the other cultivars in the same conditions. The $\left(\mathrm{K}^{+}+\mathrm{Mg}^{2+}\right) / \mathrm{Ca}^{2+}$ ratio was also increased by BERi treatment at the pre-BER stage and the resulting ratio was more than 1.6 times higher for the Japanese cultivars than 'Managua RZ'. In the healthy fruits, the same trends were found, with $\mathrm{K}^{+} / \mathrm{Ca}^{2+}$ being much higher in 'Reiyoh' than in 'Managua RZ' and 'House Momotaro'. In the two Japanese cultivars, affected fruits also tended to show higher values for both ratios.

\section{Total hydrosoluble antioxidants}

In the control condition, pre-BER stage, there was no statistical difference between all cultivars (Fig. 2A). Under the BERi treatment, only fruits of 'Managua RZ' and 'House Momotaro' had significantly increased antioxidants, with increases of $56 \%$ and $45 \%$ respectively. In 'Reiyoh' the increase was of only $37 \%$ and was not significant. The resultant antioxidant concentration in the BERi condition was the highest for 'Managua RZ', reaching $1675 \mathrm{nmol} \cdot \mathrm{g}^{-1} \mathrm{FW}$. It was intermediate for 'House Momotaro' with $1390 \mathrm{nmol} \cdot \mathrm{g}^{-1} \mathrm{FW}$ and the lowest for 'Reiyoh' with $1172.5 \mathrm{nmol} \cdot \mathrm{g}^{-1} \mathrm{FW}$. During BER appearance, there was a trend in healthy fruits to have more antioxidants in the BERi treatment than in the control (Fig. 2B). Also, 'Managua RZ' tended to have more antioxidants than the two Japanese cultivars. This increase was less important than in the pre-BER stage. In affected fruits (Fig. 2C), 'Managua RZ' tended to have more antioxidants than 'Reiyoh', which also tended to have more than 'House Momotaro'.

\section{Ascorbate concentrations}

Ascorbate redox ratios were always higher than $80 \%$, so only total ascorbate concentrations were considered 

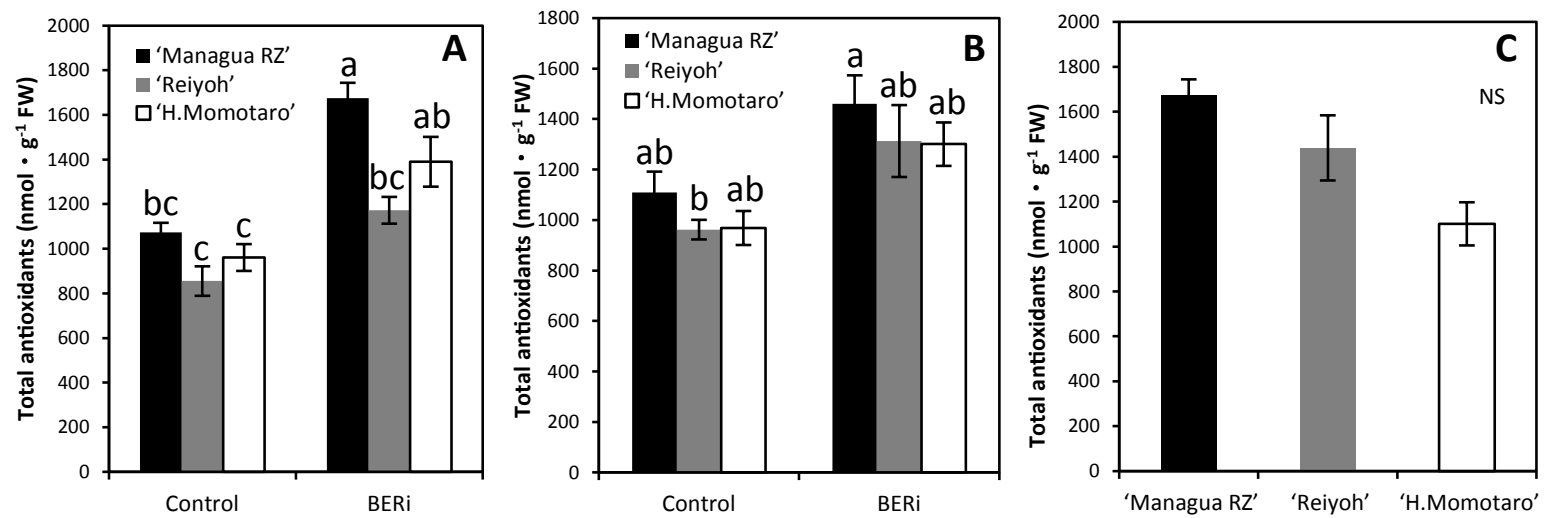

Fig. 2. Total hydrosoluble antioxidant concentration in the distal pericarp of (A) pre-BER, (B) healthy, and (C) affected tomato fruits, expressed in equivalent L-sodium ascorbate $(\mathrm{n}=5)$. NS: ANOVA was not significant $(P<0.05)$. Different letters represent a statistical difference in total hydrosoluble antioxidants $(P<0.05)$. Data are means \pm standard error $(\mathrm{SE})$.
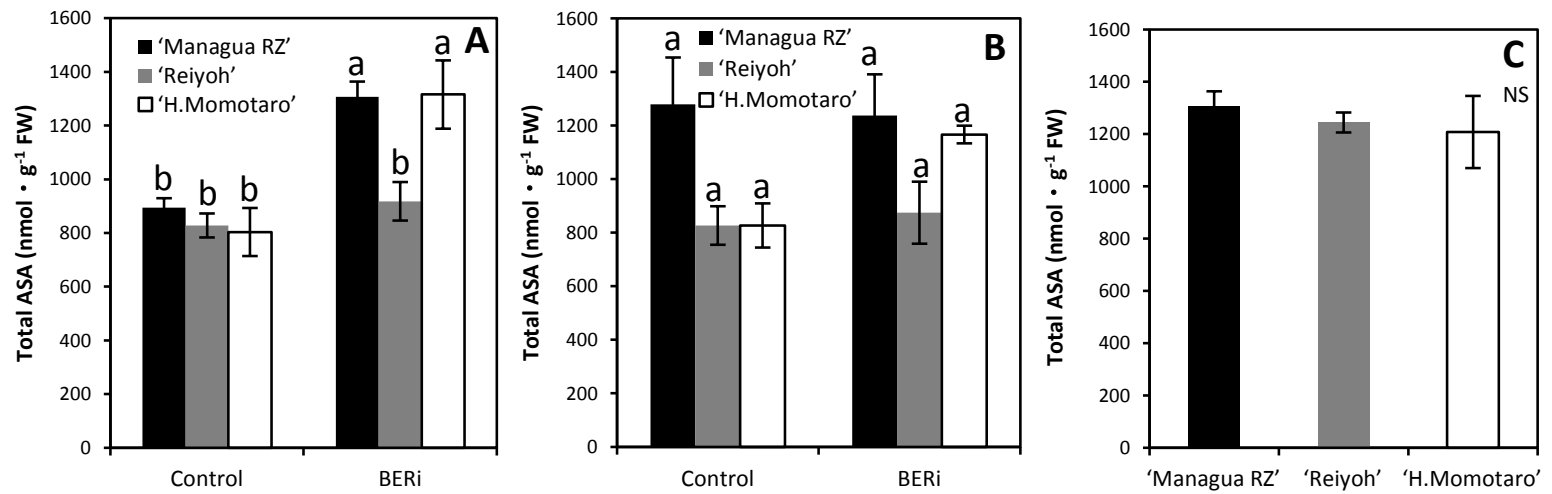

Fig. 3. Total ascorbate (ASA) concentrations in the distal pericarp of (A) pre-BER, $(B)$ healthy, and $(C)$ affected tomato fruits $(n=3-5)$. NS: ANOVA was not significant $(P<0.05)$. Different letters represent a statistical difference in total ASA $(P<0.05)$. Data are means \pm standard error (SE).

(data not shown). In the pre-BER stage control treatment, all cultivars had within $800 \mathrm{nmol} \cdot \mathrm{g}^{-1} \mathrm{FW}$ ascorbate in their distal pericarp (Fig. 3A). These concentrations were only significantly higher in 'Managua RZ' and 'House Momotaro' in the BERi treatment. In comparison with the control, the increases were of $46 \%$ and $63 \%$, respectively, making their concentrations higher than $1300 \mathrm{nmol} \cdot \mathrm{g}^{-1} \mathrm{FW}$. For 'Reiyoh', the increase was only $10.8 \%$. During symptom appearance in healthy fruits, the increase in ascorbate was not significant for any cultivars. In the BERi treatments, 'Managua RZ' and 'House Momotaro' fruits maintained their trend of having more ascorbate than 'Reiyoh', with concentrations above $1150 \mathrm{nmol}$. $\mathrm{g}^{-1} \mathrm{FW}$, while in 'Reiyoh' concentrations were below $900 \mathrm{nmol} \cdot \mathrm{g}^{-1} \mathrm{FW}$. When comparing control and BERi treatments, 'House Momotaro' tended to have more ascorbate in the BERi condition, but the two other cultivars had comparable levels (Fig. 3B). In the affected fruits, all cultivars had comparable ascorbate concentrations within $1200-1300 \mathrm{nmol} \cdot \mathrm{g}^{-1} \mathrm{FW}$ (Fig. 3C).

\section{Glutathione concentrations}

ANOVA analysis was not significant in terms of stages or fruit types (healthy and affected) for the GSSG concentration of the distal pericarp (Fig. 4, $P<$ 0.05). 'House Momotaro' showed a tendency to have more glutathione (GSH) than the other cultivars in treatments prior to symptom appearance and in healthy fruits under control treatment (Fig. 5A, B). For the BERi treatment, healthy fruits of 'Managua RZ' showed significantly more glutathione than 'Reiyoh', while 'House Momotaro' had an intermediate level. In affected fruits, the effect on cultivars was not significant (data not shown) (Fig. 5C, $P<0.05$ ). For the redox ratio of glutathione, the effect of treatment was significant (data not shown) only in healthy fruits during symptom appearance, with no substantial differences between cultivars (Fig. 6B).

\section{Discussion}

In this experiment, the BERi treatment succeeded triggering the appearance of BER fruits at the same fruit age in all 3 cultivars. However, there was a large difference between 'Reiyoh', which was highly suscep- 

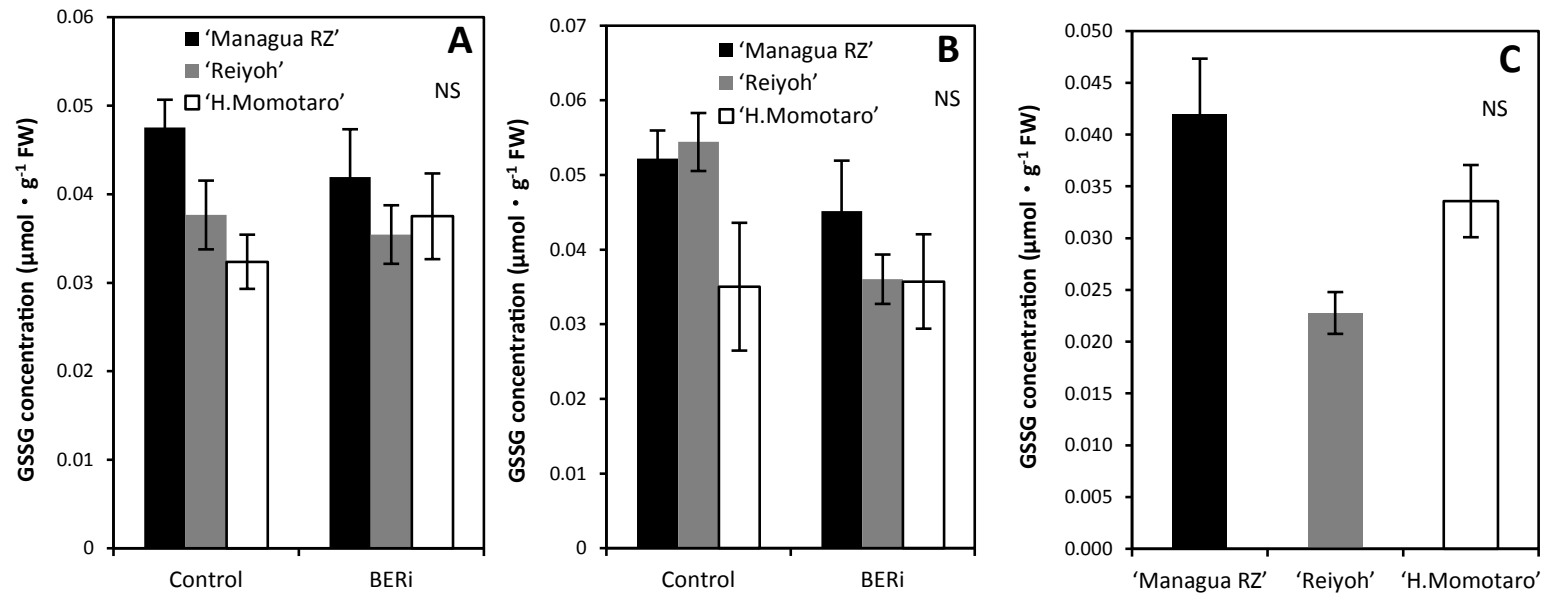

Fig. 4. Oxidized glutathione (GSSG) concentration in the distal pericarp of (A) pre-BER, (B) healthy, and $(C)$ affected tomato fruits $(n=3-5)$. NS: ANOVA was not significant $(P<0.05)$. Different letters represent a statistical difference in oxidized glutathione $(P<0.05)$. Data are means \pm standard error (SE).
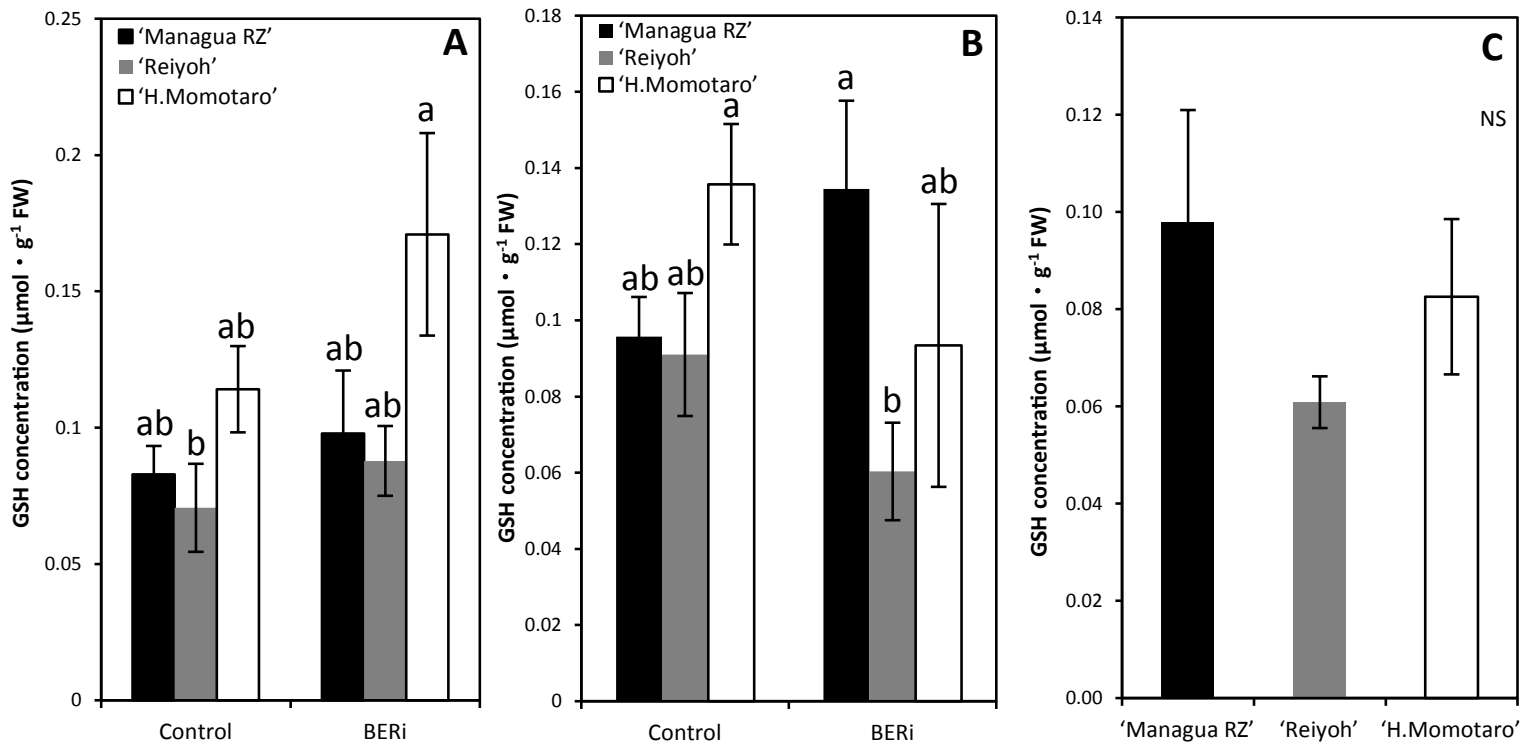

Fig. 5. Reduced glutathione (GSH) concentration in the distal pericarp of (A) pre-BER, (B) healthy, and (C) affected tomato fruits $(n=3-5)$. NS: ANOVA was not significant $(P<0.05)$. Different letters represent a statistical difference in reduced glutathione $(P<0.05)$. Data are means \pm standard error (SE).

tible, and the two other cultivars, which showed very low incidence and could be considered as unsusceptible or resistant. These results are in accordance with a previous study in which BER susceptibility was found to be variable between a range of genotypes (Adams and Ho, 1992; Ho et al., 1995).

In comparison with the control nutrient solution, the BERi nutrient solution was enriched in $\mathrm{K}^{+}, \mathrm{Mg}^{2+}$, and its EC level was increased by up to $8 \mathrm{dS} \cdot \mathrm{m}^{-1}$ with the addition of $\mathrm{NaCl}$, while $\mathrm{Ca}^{2+}$ concentration was maintained to avoid the adverse effects of $\mathrm{Ca}^{2+}$ deficiency on plants (Simon, 1978). The combination of these factors succeeded in increasing BER incidence in 'Reiyoh' to levels higher than described in the literature under comparable salt stress (Adams and Ho, 1992; Ho et al.,
1995), or by only changing the nutrient solution ratios of $\mathrm{Ca}^{2+}$ to $\mathrm{K}^{+}$(Van Der Boon, 1973) or $\mathrm{Mg}^{2+}$ (Hao and Papadopoulos, 2004). Salinity is thought to lower plant $\mathrm{Ca}^{2+}$ uptake and distribution into fruits, and the distalend part of the fruit is thought to be particularly exposed to $\mathrm{Ca}^{2+}$ deficiency (Ho and Adams, 1989), which triggers BER (Bradfield and Guttridge, 1984). The drastic reduction in fruit fresh weight indicates the level of osmotic stress that was imposed on the plants. $\mathrm{K}^{+}$ and $\mathrm{Mg}^{2+}$ enrichment were proposed to increase BER incidence by competition with $\mathrm{Ca}^{2+}$ absorption limiting its uptake, resulting in nutrient imbalances inside the fruit (Bar-Tal and Pressman, 1996; Hao and Papadopoulos, 2004; Raleigh and Chucka, 1944; Van Der Boon, 1973). 

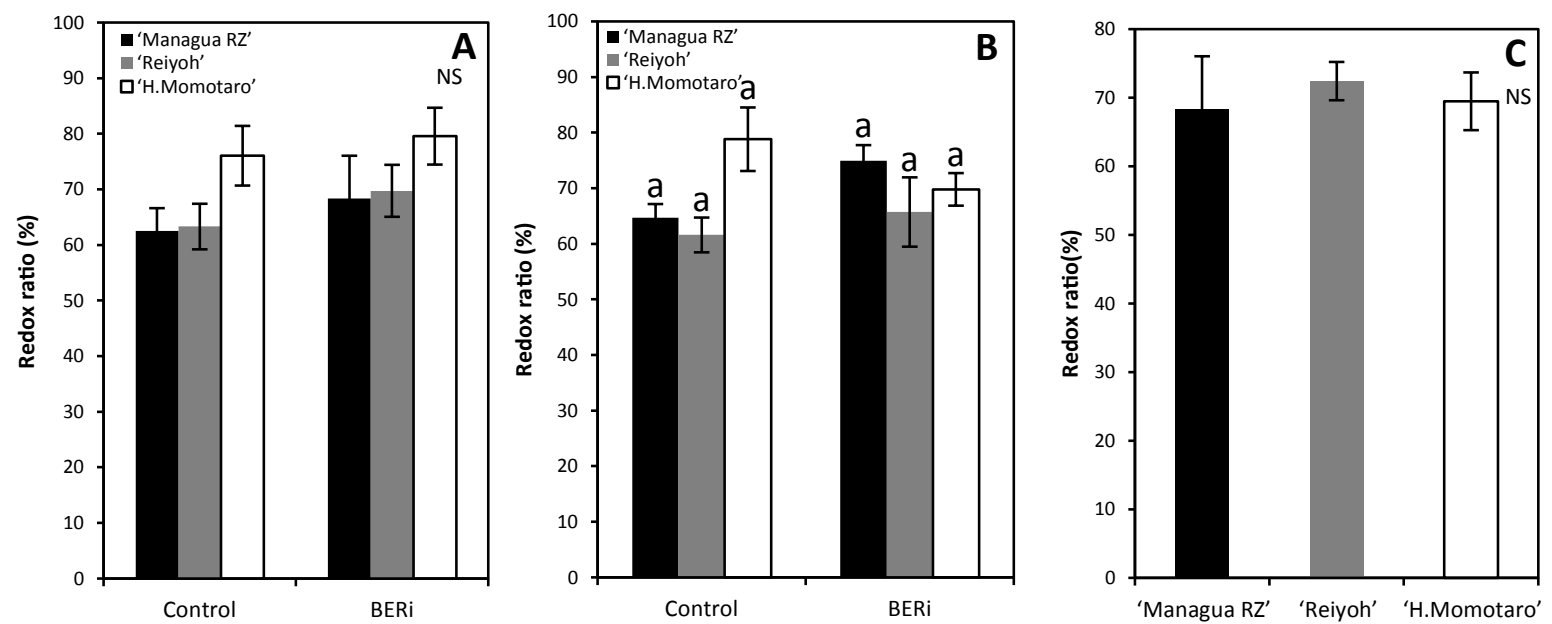

Fig. 6. Glutathione redox ratio in the distal pericarp of (A) Pre-BER, (B) healthy, and (C) affected tomato fruits ( $\mathrm{n}=3-5)$. NS: ANOVA was not significant $(P<0.05)$. Different letters represent a statistical difference in glutathione redox ratio $(P<0.05)$. Data are means \pm standard error (SE).

Nutrient solution treatment, sampling time and cultivars did not show any significant differences in fruit $\mathrm{K}^{+}$ concentrations, while $\mathrm{Mg}^{2+}$ was only significantly higher prior to symptom appearance in 'Reiyoh'. Importantly, we found no association between BER susceptibility and calcium content in pre-BER fruits, the stage which is thought to be critical for BER appearance. In fact, under the BERi condition, $\mathrm{Ca}^{2+}$ concentrations were decreased in the distal part of young pre-BER fruits. In addition, the reduction was more severe in 'Reiyoh' and 'House Momotaro' than in the Dutch cultivar. Moreover, $\mathrm{Ca}^{2+}$ concentrations measured in both Japanese cultivars were much more lower than the lowest levels found in the literature for BER-inductive conditions (Bradfield and Guttridge, 1984; De Freitas et al., 2012; Ward, 1973). BER incidence was much higher in 'Reiyoh' than in 'House Momotaro'. It was only in healthy fruits, during BER appearance, that $\mathrm{Ca}^{2+}$ levels tended to be particularly low in 'Reiyoh'. These results support the idea that $\mathrm{Ca}^{2+}$ is indeed an important factor involved in the development of BER, but that other factors are probably also involved (Saure, 2001). Interestingly, $\mathrm{K}^{+} / \mathrm{Ca}^{2+}$ and $\left(\mathrm{K}^{+}+\mathrm{Mg}^{2+}\right) / \mathrm{Ca}^{2+}$ ratios found in healthy fruits during symptom appearance were associated with BER incidence, as 'Reiyoh' showed much higher ratios than the other two cultivars. Indeed, De Freitas et al. (2015) showed that in apple fruit, bitter pit (BP), another fruit storage Ca-deficiency disorder, was associated with a high fruit $\left(\mathrm{K}^{+}+\mathrm{Mg}^{2+}\right) / \mathrm{Ca}^{2+}$ ratio. In their study, this high ratio was due to higher $\mathrm{K}^{+}$and $\mathrm{Mg}^{2+}$ concentrations in BP affected fruits of a BPsusceptible cultivar, while calcium concentrations were similar in both BP-susceptible and resistant cultivar fruits. The authors of this study proposed that this ratio probably acts by reducing $\mathrm{Ca}^{2+}$ binding sites in the cell membrane (Schönherr and Bukovac, 1973; Yermiyahu et al., 1994) and/or by promoting fruit growth which in- creases $\mathrm{Ca}^{2+}$ dilution under salt stress (Lopez and Satti, 1996). However, in our study this increased ratio was the result of lowered $\mathrm{Ca}^{2+}$ concentrations in 'Reiyoh' while the $\mathrm{K}^{+}$and $\mathrm{Mg}^{2+}$ levels were similar in all cultivars under the BERi condition. Therefore, our results support the possible involvement of increased $\mathrm{K}^{+}$and $\mathrm{Mg}^{2+}$ to $\mathrm{Ca}^{2+}$ ratios with the susceptibility to $\mathrm{Ca}^{2+}$ deficiency disorders, but without providing sufficiently strong evidence (De Freitas et al., 2015; Do Amarante et al., 2013).

In our study, under the BERi condition, pre-BER fruits tended to show more antioxidants than control fruits. Additionally, levels of antioxidants were different between cultivars. For the total hydrosoluble antioxidants, if compared to 'Reiyoh', only 'Managua RZ' had significantly more antioxidants, while 'House momotaro' tended to show more antioxidants but without significant differences. Interestingly, prior to symptom appearance, the resistant cultivars 'Managua RZ' and 'House Momotaro' showed more total ascorbate than the susceptible cultivar 'Reiyoh', while no difference was observed in the ascorbate redox status. A similar trend was maintained in healthy fruits during symptom appearance, but only for ascorbate. Also, there was no significant difference found between cultivars for the glutathione redox status. These results clearly indicate that there is a link between BER and the ROS scavenging capacity, 1 to 2 days prior to symptom appearance and the ascorbate pool appeared as a major contributor of this antioxidant capacity. This supports the proposed hypothesis that BER is the result of cell damage provoked by oxidative stress (Aktas et al., 2003). Thus, if ROS happen to be the major causal factor in BER appearance, it is possible that BER is an indirect result of a lack of ROS scavenging capacity represented by ascorbate during stress conditions, which are known to boost ROS levels. Therefore, the 
fact that BER appears at 12-15 DAA could be a consequence of the regulation of ascorbate and ROS levels in tomato fruit during its development, most specifically prior and during BER appearance stages. Accordingly, the levels of ascorbate were already reported to be the lowest around at 7 and 15 DAA in tomato fruit (Carrari et al., 2006), which further supports our hypothesis.

To confirm the results of this study, it will be important to evaluate the ROS content in this experimental system. It will also be important to evaluate cell damage by lipid peroxidation (Van Breusegem and Dat, 2006), which indicates whether there was protection from oxidative damage in BER-resistant cultivars or not compared with 'Reiyoh'. Additionally, the capacities of enzymes involved in the production and scavenging of ROS could also be measured, as they may have a major role (Mittler, 2002). Also, it can be argued that fruits affected by BER in all cultivars displayed comparable antioxidant and ascorbate levels. The assay was performed on tissues surrounding the affected area, which tended to be close to the fruit mid-section in 'Reiyoh' due to the large size of the necrosis. Affected fruits of 'Reiyoh' had more ascorbate in the proximal pericarp than the distal one (data not shown), so it is possible that the samples from them showed comparable antioxidant and ascorbate concentrations to the other cultivars because of their proximity to the peduncle side.

In conclusion, our results support the involvement of ROS as a major protagonist in BER appearance. In our experiment, BER-resistant cultivars showed a larger increase in their ROS scavenging capacity, represented by ascorbate, in response to BER-inductive growth conditions. These differences in ascorbate antioxidant capacity among cultivars were observed right before the symptoms started to appear in the distal part of tomato fruits and tended to be maintained during symptom appearance. It is unclear whether these differences are due to a concentration effect by the limitation of fruit size or the activation of stress-resistance mechanisms. Also, it seems that the critical phase for BER initiation is around 10 DAA under salt stress, which suggests that there is a peak of ROS production during that stage. Thus, further studies should be performed to confirm the occurrence of actual redox stress. Higher $\mathrm{K}^{+} / \mathrm{Ca}^{2+}$ and $\left(\mathrm{K}^{+}+\mathrm{Mg}^{2+}\right) / \mathrm{Ca}^{2+}$ ratios and a tendency to have less $\mathrm{Ca}^{2+}$ were only observed in 'Reiyoh' during symptom appearance. These nutrient imbalances could be involved in increasing the instability of the cell membrane as mentioned above. We hypothesize that these cell nutrient imbalances may be a trigger for cell disintegration after damage by excessive ROS in the tissues affected.

\section{Acknowledgements}

We wish to thank Patricia Ballias from the metabolism team of INRA Bordeaux-Aquitaine for her assis- tance with the metabolites analysis. We would like to thank Mizuki Matsuoka from the Agricultural and Forestry Research Center of the University of Tsukuba for his technical assistance and advice on the cultivation of tomatoes in the greenhouse.

\section{Literature Cited}

Adams, P. and L. C. Ho. 1992. The susceptibility of modern tomato cultivars to blossom-end rot in relation to salinity. J. Hort. Sci. 67: 827-839.

Aktas, H., L. Karni, B. Aloni and A. Bar-Tal. 2003. Physiological and biochemical mechanisms leading to blossom-end rot in greenhouse-grown peppers, irrigated with saline solution. Acta Hortic. 609: 81-88.

Bar-Tal, A. and E. Pressman. 1996. Root restriction and potassium and calcium solution concentrations affect dry-matter production, cation uptake, and blossom-end rot in greenhouse tomato. J. Amer. Soc. Hort. Sci. 121: 649-655.

Bradfield, E. G. and C. G. Guttridge. 1984. Effects of night-time humidity and nutrient solution concentration on the calcium content of tomato fruit. Sci. Hortic. 22: 207-217.

Carrari, F., C. Baxter, B. Usadel, E. Urbanczyk-wochniak, M. Zanor, A. Nunes-nesi, V. Nikiforova, D. Centero, A. Ratzka, M. Pauly, L. J. Sweetlove and A. R. Fernie. 2006. Integrated analysis of metabolite and transcript levels reveals the metabolic shifts that underlie tomato fruit development and highlight regulatory aspects of metabolic network behavior. Plant Physiol. 142: 1380-1396.

D’Amico, M. L., R. Izzo, F. Navari-Izzo, F. Tognoni and A. Pardossi. 2003. Sea water irrigation: antioxidants and quality of tomato berries (Lycopersicon esculentum Mill.). Acta Hortic. 609: 59-65.

De Freitas, S. T., C. V. T. Do Amarante and E. J. Mitcham. 2015. Mechanisms regulating apple cultivar susceptibility to bitter pit. Sci. Hortic. 186: 54-60.

De Freitas, S. T., A. K. Handa, Q. Wu, S. Park and E. J. Mitcham. 2012. Role of pectin methylesterases in cellular calcium distribution and blossom-end rot development in tomato fruit. Plant J. 71: 824-835.

Do Amarante, C. V. T., A. Miqueloto, S. T. De Freitas, C. A. Steffens, J. P. G. Silveira and T. R. Corrêa. 2013. Fruit sampling methods to quantify calcium and magnesium contents to predict bitter pit development in 'Fuji' apple: A multivariate approach. Sci. Hortic. 157: 19-23.

Francesco, S., O. Ayala, A. Bonasia and P. Santamaria. 2005. Antioxidant properties and health benefits of tomato. p. 159 179. In: J. N. Govil, V. K. Singh and C. Aarunachalam (eds.). Recent Progress in Medicinal Plants Volume 13: Search for Natural Drugs. Studium press LLC, Texas.

Geraldson, C. M. 1955. The use of calcium for control of blossom-end rot of tomatoes. Florida Agric. Exp. Stn. J. Ser. 410: $197-202$.

Griffith, O. W. 1980. Determination of glutathione and glutathione disulfide using glutathione reductase and 2vinylpyridine. Anal. Biochem. 106: 207-212.

Hao, X. and A. P. Papadopoulos. 2004. Effects of calcium and magnesium on plant growth, biomass partitioning, and fruit yield of winter greenhouse tomato. HortScience 39: 512 515 .

Ho, L. C. and P. Adams. 1989. Effects of diurnal changes in the salinity of the nutrient solution on the accumulation of calcium by tomato fruit. Ann. Bot. 64: 373-382.

Ho, L. C., P. Adams, X. Z. Li, H. Shen, J. Andrews and Z. H. Xu. 1995. Responses of Ca-efficient and Ca-inefficient tomato 
cultivars to salinity in plant growth, calcium accumulation and blossom-end rot. J. Hort. Sci. 70: 909-918.

Ioannidi, E., M. S. Kalamaki, C. Engineer, I. Pateraki, D. Alexandrou, I. Mellidou, J. Giovannonni and A. K. Kanellis. 2009. Expression profiling of ascorbic acid-related genes during tomato fruit development and ripening and in response to stress conditions. J. Exp. Bot. 60: 663-678.

Leyva, R., C. Constán-Aguilar, B. Blasco, E. Sánchez-Rodríguez, T. Soriano and J. M. Ruíz. 2013. A fogging system improves antioxidative defense responses and productivity in tomato. J. Amer. Soc. Hort. Sci. 138: 267-276.

Lopez, M. V. and S. M. E. Satti. 1996. Calcium and potassiumenhanced growth and yield of tomato under sodium chloride stress. Plant Sci. 114: 19-27.

Marc, F., A. Davin, L. Deglène-benbrahim, C. Ferrand, M. Baccaunaud and P. Fritsch. 2016. Méthodes d' évaluation du potentiel antioxydant dans les aliments. Med. Sci. 20: 458 463.

Marschner, H. 1995. Mineral nutrition of higher plants, 2nd edn. Academic press, London.

Massot, C., D. Bancel, F. L. Lauri, V. Truffault, P. Baldet, R. Stevens and H. Gautier. 2013. High temperature inhibits ascorbate recycling and light stimulation of the ascorbate pool in tomato despite increased expression of biosynthesis genes. PLoS ONE 8: e84474.

Mittler, R. 2002. Oxidative stress, antioxidants and stress tolerance. Trends Plant Sci. 7: 405-410.

Murshed, R., F. Lopez-Lauri and H. Sallanon. 2013. Effect of water stress on antioxidant systems and oxidative parameters in fruits of tomato (Solanum lycopersicon L, cv. Micro-tom). Physiol. Mol. Biol. Plants 19: 363-378.

Murshed, R., F. Lopez-Lauri and H. Sallanon. 2014. Effect of salt stress on tomato fruit antioxidant systems depends on fruit development stage. Physiol. Mol. Biol. Plants 20: 15-29.

Nonami, H., T. Fukuyama, M. Yamamoto, L. Yang and Y. Hashimoto. 1995. Blossom-end rot of tomato plants may not be directly caused by calcium deficiency. Acta Hortic. 396: $107-114$.

Olle, M. and I. Bender. 2009. Causes and control of calcium deficiency disorders in vegetables: A review. J. Hort. Sci. Biotech. 84: 577-584.

Pill, W. G. and V. N. Lambeth. 1980. Effects of soil water regime and nitrogen form on blossom-end rot, yield, water relations and elemental composition of tomato. J. Amer. Soc. Hort. Sci. 105: 730-734.

Premuzic, Z., M. Bargiela, A. Garcia, A. Rendina and A. Iorio. 1998. Calcium, iron, potassium, phosphorus, and vitamin C content of organic and hydroponic tomatoes. HortScience 33: 255-257.

Raleigh, S. M. and J. A. Chucka. 1944. Effect of nutrient ratio and concentration on growth and composition of tomato plants and on the occurrence of blossom-end rot of the fruit. Plant Physiol. 19: 671-678.
Robbins, W. 1937. Relation of nutrient salt concentration to growth of tomato and to the incidence of blossom-end rot of the fruit. Plant Physiol. 12: 21-50.

Saure, M. C. 2001. Blossom-end rot of tomato (Lycopersicon esculentum Mill.) - a calcium-or a stress-related disorder? Sci. Hortic. 90: 193-208.

Schönherr, J. and M. J. Bukovac. 1973. Ion exchange properties of isolated tomato fruit cuticular membrane: Exchange capacity, nature of fixed charges and cation selectivity. Planta 109: 73-93.

Simon, E. W. 1978. The symptoms of calcium deficiency in plants. New Phytol. 80: 1-5.

Spurr, A. R. 1959. Anatomical aspects of blossom-end rot in the tomato with special reference to calcium nutrition. Hilgardia 28: 269-292.

Stevens, R., M. Buret, C. Garchery, Y. Carretero and M. Causse. 2006. Technique for rapid, small-scale analysis of vitamin C levels in fruit and application to a tomato mutant collection. J. Agric. Food Chem. 54: 6159-6165.

Suzuki, K., M. Shono and Y. Egawa. 2003. Localization of calcium in the pericarp cells of tomato fruits during the development of blossom-end rot. Protoplasma 222: 149-156.

Tabatabaie, S. J., P. J. Gregory and P. Hadley. 2004. Uneven distribution of nutrients in the root zone affects the incidence of blossom end rot and concentration of calcium and potassium in fruits of tomato. Plant Soil 258: 169-178.

Taylor, M. D. and S. J. Locascio. 2004. Blossom-end rot: A calcium deficiency. J. Plant Nutr. 27: 123-139.

Torres, C. A. and P. K. Andrews. 2006. Developmental changes in antioxidant metabolites, enzymes, and pigments in fruit exocarp of four tomato (Lycopersicon esculentum Mill.) genotypes: $\beta$-carotene, high pigment-1, ripening inhibitor, and 'Rutgers'. Plant Physiol. Biochem. 44: 806-818.

Torres, C. A., P. K. Andrews and N. M. Davies. 2006. Physiological and biochemical responses of fruit exocarp of tomato (Lycopersicon esculentum Mill.) mutants to natural photooxidative conditions. J. Exp. Bot. 57: 1933-1947.

Van Breusegem, F. and J. F. Dat. 2006. Reactive oxygen species in plant cell death. Plant Physiol. 141: 384-390.

Van Der Boon, J. 1973. Influence of K/Ca ratio and drought on physiological disorders in tomato. Neth. J. Agric. Sci. 21: 56-67.

Van Goor, B. J. 1968. The role of calcium and cell permeability in the disease blossom-end rot of tomatoes. Physiol. Plant. 21: $1110-1121$.

Ward, G. M. 1973. Causes of blossom-end rot of tomatoes based on tissue analysis. Can. J. Plant Sci. 53: 169-174.

Yermiyahu, U., S. Nir, G. Ben-Hayyim and U. Kafkafi. 1994. Quantitative competition of calcium with sodium or magnesium for sorption sites on plasma membrane vesicles of melon (Cucumis melo L.) root cells. J. Membr. Biol. 138: 55-63. 